\title{
Determination of Uranium and Thorium in Aluminum by Inductively Coupled Plasma Mass Spectrometry
}

\author{
Shoji Kozuka, Yuji Yamada, Miyuki Takenaka, Masaru Hayashi and Hideki Matsunaga \\ Environmental Engineering Laboratory, Research and Development Center, Toshiba Corporation, \\ Komukai-Toshiba, Saiwai, Kawasaki 210, Japan
}

Keywords Inductively coupled plasma mass spectrometry, aluminum, ion exchange, uranium, thorium

\begin{abstract}
Aluminum is used as an interconnect material for large-scale integrated circuits. Inherent impurities frequently cause problems with electrical resistance and diffusion in semiconductor devices. In particular, it has been reported that uranium and thorium existing in a sample cause problems with regard to soft errors; ejecting $\alpha$-particles. ${ }^{1}$ It is thus necessary to establish a determination method for trace amounts of uranium and thorium. There are a number of reliable methods for analyzing high-purity aluminum: for example, neutronactivation analysis, glow-discharge mass spectrometry, secondary ion mass spectrometry and inductively coupled plasma atomic emission spectrometry. ${ }^{2}$ However, these methods have inadequate sensitivity for the determination of uranium and thorium, and are not useful under ordinary laboratory conditions, and need reference samples. On the other hand, inductively coupled plasma mass spectrometry (ICP-MS) has been used to determine trace amounts of uranium and thorium. ${ }^{3,4}$ However, it has been said that the aluminum matrix causes ion-count suppression in the determination of traceable uranium and thorium, and that this effect is in proportion to the matrix concentration in the sample solution. ${ }^{5}$ Thus, uranium and thorium must be separated from aluminum by a coprecipitation method, an ion-exchange method, a solvent extraction method, etc. ${ }^{4,6}$ The purpose of this study was to establish a method to accurately determine uranium and thorium in aluminum by ICP-MS combined with an ion-exchange method.
\end{abstract}

\section{Experimental}

\section{Apparatus}

ICP-MS measurements were carried out using an SPQ-8000A (Seiko Instrument, Inc., Chiba, Japan). The operating conditions are given in Table 1. The ion lenses and mass resolutions were set by tuning so as to yield the maximum response for lead. Acid decom-
Table 1 Operating conditions for the ICP-MS instrument

$\begin{array}{ll}\text { Plasma power } & 1.3 \mathrm{~kW} \\ \text { Reflected power } & <10 \mathrm{~W} \\ \text { Coolant argon gas } & 181 \mathrm{~min}^{-1} \\ \text { Auxiliary argon gas } & 1.01 \mathrm{~min}^{-1} \\ \text { Carrier argon gas } & 0.41 \mathrm{~min}^{-1} \\ \text { Carrier argon pressure } & 2.2 \mathrm{~kg} \mathrm{~cm}^{-2} \\ \text { Sampling depth } & 13 \mathrm{~mm} \\ \text { Data acquisition } & \text { peak jumping mode } \\ \text { Dwell time } & 100 \mathrm{~ms} \\ \text { Accumulation } & 50 \text { times } \\ \text { Channel width } & 3 \mathrm{channel} \\ \text { Repetition } & 3 \text { times } \\ \text { Measurement isotopes } & \\ \quad \text { Uranium 238 } & \\ \text { Thorium 232 } & \end{array}$

position of the sample was carried out in a polytetrafluoroethylene (PTFE)-sealed vessel with a capacity of $30 \mathrm{ml}$ (i.d. $25 \mathrm{~mm}$, Savillex Co., MN, USA).

\section{Reagents}

The resin used was of anion exchange type form MCI GEL CA08P 75 to $150 \mu \mathrm{m}$ (Mitsubishi Chemical Co., Tokyo, Japan). Polypropylene columns of $118 \mathrm{~mm}$ in length $\times 10 \mathrm{~mm}$ inner diameter with a sintered polypropylene filter at the bottom were obtained from Muromachi Chemical Inc. (Tokyo, Japan). These columns contained $5 \mathrm{ml}$ of slurry resin. They were conditioned by passing $9 \mathrm{~mol} \mathrm{l}^{-1}$ hydrochloric acid and $7 \mathrm{~mol} \mathrm{l}^{-1}$ nitric acid, respectively, through the columns before use. A standard stock solution for uranium and thorium $\left(10 \mu \mathrm{g} \mathrm{ml}^{-1}\right.$ in $5 \%$ nitric acid) was used for XSTC-13 (SPEX Industries Inc., NJ, USA). The calibration concentrations used were 0.1 and $1 \mathrm{ng} \mathrm{ml}^{-1}$ in $1 \mathrm{~mol} \mathrm{l}^{-1}$ nitric acid. All of the acids used were of superanalytical grade (Tama Pure AA-100, Tama Chemical, Inc., Kawasaki, Japan). Distilled deionized water was used throughout. All of the pretreatment was carried 
out in a class-1000 clean room equipped with a clean draft.

\section{Procedure}

Decomposition of aluminum. First, $1 \mathrm{~g}$ of $c a .5 \mathrm{~mm} \times 5$ $\mathrm{mm}$ chips was decomposed with $20 \mathrm{ml}$ of $9 \mathrm{~mol} \mathrm{l}^{-1}$ hydrochloric acid in a PTFE-sealed vessel on a hot plate at $200^{\circ} \mathrm{C}$ for $3 \mathrm{~h}$. After decomposition was complete, the vessel was left at room temperature.

Separation of uranium. All of the decomposed solution was transferred to a PTFE bottle and loaded into the column at a flow rate of $1.0 \mathrm{ml} \mathrm{min}$. . Next, $5 \mathrm{ml}$ of $9 \mathrm{~mol} \mathrm{l}^{-1}$ hydrochloric acid, which was used to wash the PTFE bottle, was loaded. Then, $30 \mathrm{ml}$ of $6 \mathrm{moll}^{-1}$ hydrochloric acid was loaded to remove the remaining adsorbed aluminum. Finally, $40 \mathrm{ml}$ of $1 \mathrm{~mol} \mathrm{l}^{-1}$ hydrochloric acid was loaded to elute the uranium. This effluent solution was reserved in the PTFE bottle. Then, $0.1 \mathrm{ml}$ of $3 \mathrm{moll}^{-1}$ sulfuric acid was added to prevent any adsorption onto the bottom of the bottle when the solution was concentrated by heating at $200^{\circ} \mathrm{C}$ to a low volume, fumes of sulfuric acid appeared. The residual was dissolved in $5 \mathrm{ml}$ of $1 \mathrm{~mol} \mathrm{l}^{-1}$ nitric acid. Finally, the solution was analyzed by ICP-MS using a calibration method.

Separation of thorium. All of the decomposed solution was transferred to a PTFE bottle and evaporated to the dry state on a hot plate at $130^{\circ} \mathrm{C}$. The residual was dissolved in $20 \mathrm{ml}$ of $7 \mathrm{~mol} \mathrm{l}^{-1}$ nitric acid. This operation was performed two times to completely expel hydrochloric acid. The sample dissolved by $20 \mathrm{ml}$ of $7 \mathrm{~mol}^{-1}$ nitric acid was loaded into the column at a flow rate of $1.0 \mathrm{ml} \mathrm{min}^{-1}$. Next, $5 \mathrm{ml}$ of $7 \mathrm{~mol} \mathrm{l}^{-1}$ nitric acid used to wash the bottle was loaded. Then, $30 \mathrm{ml}$ of $7 \mathrm{~mol} \mathrm{l}^{-1}$ nitric acid was loaded to remove the remaining adsorbed aluminum. Finally, $40 \mathrm{ml}$ of $1 \mathrm{moll}^{-1}$ nitric acid was loaded to elute the thorium. This effluent solution was reserved in the PTFE bottle. Then, $0.1 \mathrm{ml}$ of $3 \mathrm{~mol} \mathrm{l}^{-1}$ sulfuric acid was added to prevent any adsorption onto the bottom of the bottle when the solution was concentrated by heating at $200^{\circ} \mathrm{C}$ to a low volume, when fumes of sulfuric acid appeared. The residual was dissolved in $5 \mathrm{ml}$ of $1 \mathrm{~mol} \mathrm{l}^{-1}$ nitric acid. Finally, the solution was analyzed by ICP-MS using a calibration method.

\section{Results and Discussion}

\section{Sample decomposition and matrix separation}

Though aluminum is generally decomposed by several acids or alkali solutions, high-purity aluminum is difficult to decompose in a beaker on a hot plate. Also, if hydrofluoric acid is used for the decomposition or in the separation techniques, there is a possibility of precipitation of thorium fluoride. We thus did not use hydrofluoric acid in this experiment. Although copper, cobalt, hydrogen peroxide etc., which are reactionacceleration agents, can also be added to accomplish rapid decomposition, the uranium and thorium existing in these agents are thought to increase the blank value. In this experiment we employed acid pressure decomposition using a PTFE-sealed vessel, resulting in less contamination and a smaller acid volume. Since sample decomposition using $6 \mathrm{~mol} \mathrm{l}^{-1}$ hydrochloric acid was insufficient, $20 \mathrm{ml}$ of $9 \mathrm{~mol} \mathrm{l}^{-1}$ hydrochloric acid was used for $1 \mathrm{~g}$ samples. If the impurity concentrations at the $\mathrm{ng} \mathrm{g}^{-1}$ level are to be determined by ICP-MS, the aluminum matrix must be separated from uranium and thorium, due to matrix suppression. When a $1 \mathrm{~g}$ sample was decomposed and then diluted to $5 \mathrm{ml}$, the matrix concentration was $200 \mathrm{mg} \mathrm{ml}^{-1}$. At this concentration, the signal ion counts were suppressed to less than about $30 \%$ of the ion counts of the non-matrix measurements. In order to overcome this problem, matrix-separation techniques, for examplé, coprecipitation and solventextraction, can be used. We employed an ion-exchange separation method in which several kinds of acid solutions could be selected. The eluent solution of a mixture of an acid and a complexing agent salt is highly effective for separating uranium and thorium. ${ }^{7,8}$ However, the affect on uranium and thorium by the complexing agent could not be ignored for $\mathrm{ng} \mathrm{g}^{-1}$ level determinations. The separation techniques of simple acid media were selected in order to avoid an increase in the blank value, though these were not new methods. However, the elution behaviors have not been adequately studied at the low-concentration levels for uranium and thorium, which are contained in a high-purity metal. Although aluminum was not adsorbed to the anion exchange resin by hydrochloric acid and nitric acid, uranium was adsorbed by $9 \mathrm{~mol} \mathrm{l}^{-1}$ hydrochloric acid and thorium was adsorbed by $7 \mathrm{moll}^{1-1}$ nitric acid., ${ }^{9} 10$ The adsorbed uranium and thorium could be eluted by $1 \mathrm{moll}^{-1}$ hydrochloric acid and $1 \mathrm{~mol} \mathrm{l}^{-1}$ nitric acid, respectively.9,10 In order to evaluate the separation conditions, fractions of $5 \mathrm{ml}$ were taken from the beginning of the loading sample solution which contained $1 \mathrm{~g}$ gf aluminum and $100 \mathrm{ng}$ of uranium or thorium, and the concentrations were determined. Figures 1 and 2 show elution curves for uranium and thorium in this experiment. It is evident that aluminum could be separated from uranium and thorium by using several acid concentrations. Constant concentrations of uranium and thorium were also added to the dissolved aluminum in order to examine the recovery of the established method. Recoveries of uranium and thorium of more than 95\% could be achieved, and the method was thus verified to be practical and effective for aluminum separation.

\section{Analysis of reference samples}

The method developed in this study was applied to the analysis of a standard reference aluminum sample prepared by the Japan Society for Analytical Chemistry. The results are given in Table 2 . X1, X2 and X3 are analytical replications of the same sample. The three repeated values are in reasonable agreement with the certified values. The detection limits for both elements 


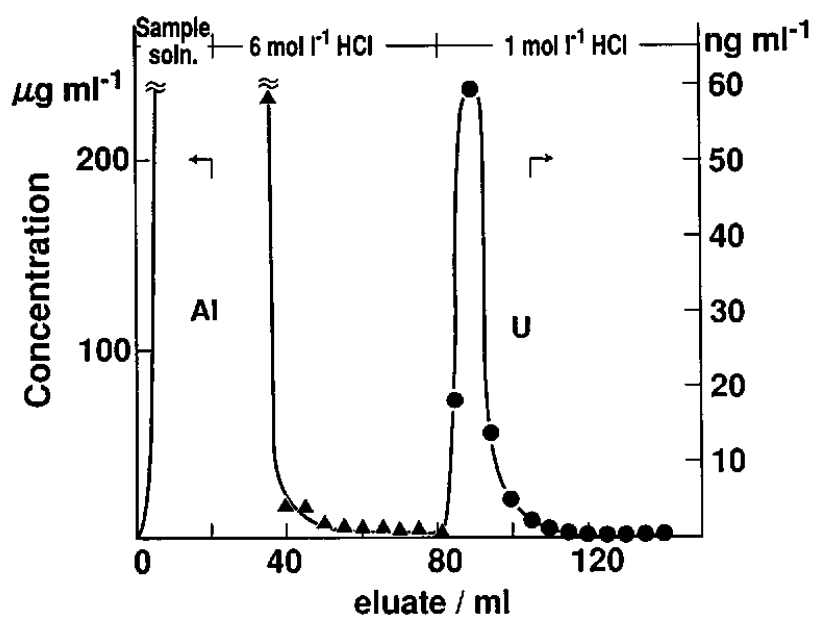

Fig. 1 Elution curves of uranium and aluminum. $\Delta, \mathrm{Al}(1 \mathrm{~g})$; -, U (100 ng). Ion-exchange resin: MCI GEL CA08P. Chloride form (75 to $150 \mu \mathrm{m})$. Polypropylene column containing $5 \mathrm{ml}$ of resin; diameter, $10 \mathrm{~mm}$. Flow rate: $1 \mathrm{ml} \mathrm{min}{ }^{-1}$.

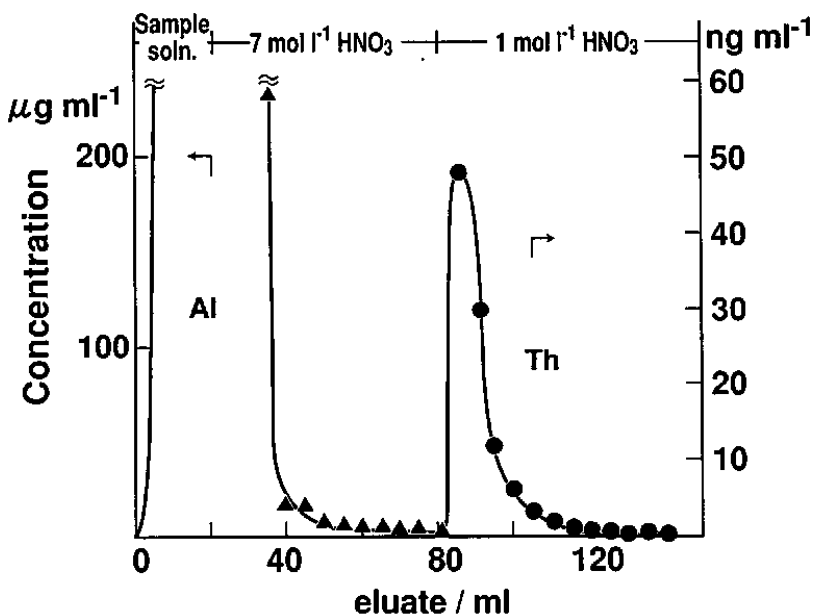

Fig. 2 Elution curves of thorium and aluminum. $\Delta, \mathrm{Al}(1 \mathrm{~g})$; - Th (100 ng). Ion-exchange resin: MCI GEL CA08P. Nitrate form ( 75 to $150 \mu \mathrm{m}$ ). Polypropylene column containing $5 \mathrm{ml}$ of resin; diameter, $10 \mathrm{~mm}$. Flow rate: $1 \mathrm{ml}$ $\min ^{-1}$.

Table 2 Results of an analysis of high-purity aluminum

\begin{tabular}{|c|c|c|c|c|c|c|}
\hline \multirow{2}{*}{ Sample } & \multirow{2}{*}{ Element } & \multicolumn{4}{|c|}{ Concentration/ $/ \mathrm{ng} \mathrm{g}^{-1}$} & \multirow{2}{*}{$\begin{array}{c}\text { Certified } \\
\text { value } / \text { ng g }^{-1}\end{array}$} \\
\hline & & $\mathrm{X} 1$ & $\mathrm{X} 2$ & $\mathrm{X3}$ & av. & \\
\hline \multirow[t]{2}{*}{ A } & Uranium & 0.099 & 0.10 & 0.10 & 0.10 & $0.10 \pm 0.01$ \\
\hline & Thorium & 0.069 & 0.081 & 0.080 & 0.077 & $0.086 \pm 0.037$ \\
\hline \multirow[t]{2}{*}{ B } & Uranium & 1.1 & 1.0 & 0.99 & 1.0 & $1.0 \pm 0.1$ \\
\hline & Thorium & 1.6 & 1.4 & 1.4 & 1.5 & $1.7 \pm 0.4$ \\
\hline \multirow[t]{2}{*}{$\mathrm{C}$} & Uranium & 6.0 & 5.9 & 6.2 & 6.0 & $5.5 \pm 0.8$ \\
\hline & Thorium & 9.3 & 9.7 & 8.8 & 9.3 & $9.8 \pm 1.7$ \\
\hline
\end{tabular}

were $0.02 \mathrm{ng} \mathrm{g}^{-1}$ in this experiment. The relative standard deviation for three repeated analysis ranged from 1.0 to $8.3 \%$. This method is useful for the determination of traces of uranium and thorium in high-purity aluminum. ICP-MS combined with an ion-exchange method can be capable of measuring impurities in other high-purity materials, for example, tungsten, molybdenum, tantalum, copper et al. which are used for semiconductor devices.

This work was carried out as a cooperative experiment of the Japan Society for Analytical Chemistry. The authors wish to thank Professor Shoji Hirai of Musashi Institute of Technology for his useful suggestions.

\section{References}

1. T. C. May and M. H. Wood, Ann. Proc. Reliab. Phys. (Symp.), 16, 33 (1978).
2. G. Kudermann, K.-H. Blaufuss, C. Luehrs, W. Vielhaber and U. Collisi, Fresenius J. Anal. Chem., 343, 734 (1992).

3. S. Kozuka, M. Kon, M. Hayashi and H. Matsunaga, Bunseki Kagaku, 42, T19 (1993).

4. Y. Nakamura, Y. Kobayashi and Y. Kakurai, Bunseki Kagaku, 42, 525 (1993).

5. H. Kawaguchi, T. Tanaka, T. Nakamura, M. Morishita and A. Mizuike, Anal. Sci., 3, 305 (1987).

6. K. Takeda, T. Yamaguchi, H. Akiyama and T. Masuda, Analyst [London], 116, 501 (1991).

7. H. Hamaguchi, A. Ohuchi, T. Shimizu, N. Onuma and R. Kuroda, Anal. Chem., 36, 2304 (1964).

8. R. Kuroda and T. Seki, Fresenius' Z. Anal. Chem., 300, 107 (1980).

9. K. A. Kraus and F. Nelson, Proc. Int. Conf. Peaceful Uses At. Energy, Geneva, 7, 113 (1956).

10. J. P. Faris and R. F. Buchanan, Anal. Chem., 36, 1157 (1964). 